\title{
CITY DESIGN: HOUSING NEIGHBOURHOOD PROJECT METHODOLOGIES
}

\author{
A. Virtudes \\ CIAUD, Research Centre for Architecture, Urbanism and Design, University of Lisbon \\ (PORTUGAL)
}

\begin{abstract}
City design is a subject taught under the subject of Architecture. This paper aims to present the results of a neighbourhood housing project which was done as part of the Urban Planning discipline in the $4^{\text {th }}$ year of a Master Degree in Architecture. This project was prepared using a methodological approach based on the analysis of urban morphological elements and the continuity requirements in between them. The case study area is a peripheral housing neighbourhood, where the majority of buildings are single houses. Among its most problematic aspects is the fact that this is a mono-functional zone, with no diversity of recreational activities, a shortage of green spaces, and lack of commercial places. The urban continuity in between this block and the city is weak based upon a car lane with no sidewalks for pedestrians nor cycling paths. The most favourable conditions are the low density of existing buildings, the topography being flat and the social cohesion of local inhabitants. The urban design solutions propose the end of the existent urban voids, the continuity of the urban fabric with the city centre, the creation of new functional buildings including shops, offices and public spaces for sport activities.
\end{abstract}

Keywords: Cities design, housing neighbourhoods, project methodologies, urban solutions.

\section{INTRODUCTION}

Every academic year international students are coming here as part of exchange programmes from European universities, attending the Master Degree in Architecture. They are mainly coming from European countries as part of the Erasmus programme and from other countries such as Brazil or African Portuguese speaking countries, like Angola or Cape Verde Islands or even from Asia, in particular East Timor, under agreements that exist between these countries' universities and Portuguese higher education institutions. For the institutions, these students represent a challenge in particular how to promote their integration among the Portuguese pupils and the higher education system.

On the subject of urban planning as part of the Masters Degree in Architecture, a set of innovative approaches are being put into practice in order to promote the integration of international students. This integration refers not only to social and community skills in the university environment but also to scientific knowledge regarding the Portuguese spatial planning system framework.

In summary, the city projects have to follow the rules of these two municipal planning instruments, proposing urban design solutions in order to rethink this neighbourhood on the outskirts of the main city.

\section{RESEARCH METHODOLOGY FOCUSED ON SUBURBAN DISTRICTS}

The first step of the chosen methodology, in presenting a city project keeping the planning rules, was the diagnosis of the case study area. This research step - Diagnosis of case study area - comprises two phases: the characterization of the area and the survey of the planning rules for the case study area. The diagnosis of an urban area should be based on an observation survey being done in situ. The observation is an important part of the planning process, given that if the theoretical approach does not correspond with that which is observed, then the theory should be reconsidered [1]. In the case of the Urban Planning Unit, the case study area was Covelo neighbourhood district, on the outskirts of the city of Covilhã in Serra da Estrela, in the Interior region of Portugal, near the border with Spain. According to the Portuguese national statistics (2011), the municipality of Covilhã comprises about 50.000 inhabitants as a whole. The majority of them are settled along to the urban area of the hillside of Serra da Estrela mountain (Figure 1). 


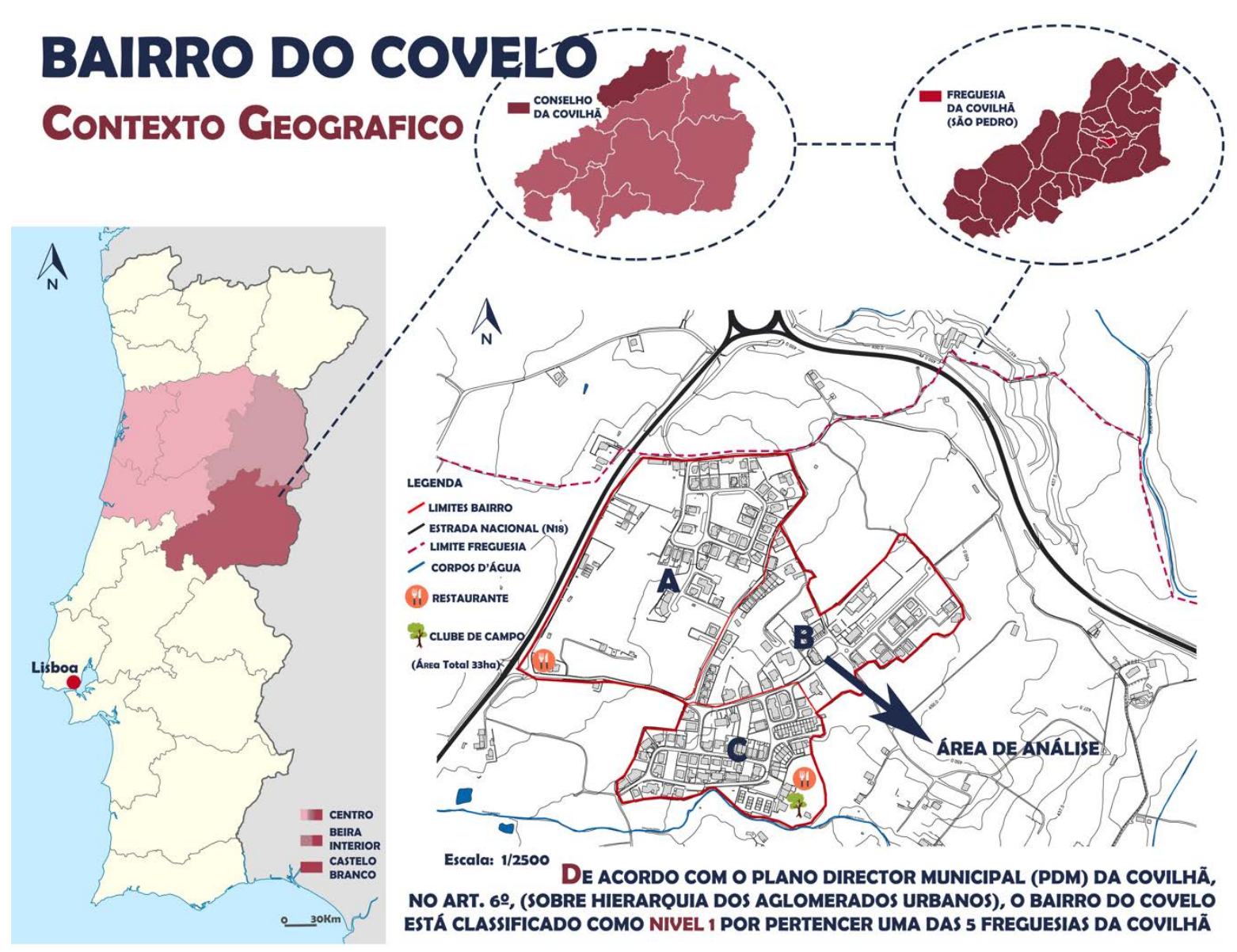

Figure 1: Case study area in Covilhã, Portugal: Localization map (Source: Students group -Bruno Ferreira, João Calheiros, Marta Nunes and Paulo Sá - Urban Planning Unit).

\section{CITY PROJECT PROPOSALS}

The case study area (Figures 2 and 3 ) has about 33 hectares organized in three main zones: $A, B$, and $\mathrm{C}$. For example, the zone $\mathrm{B}$ has about 11 hectares and it comprises 61 existing buildings.

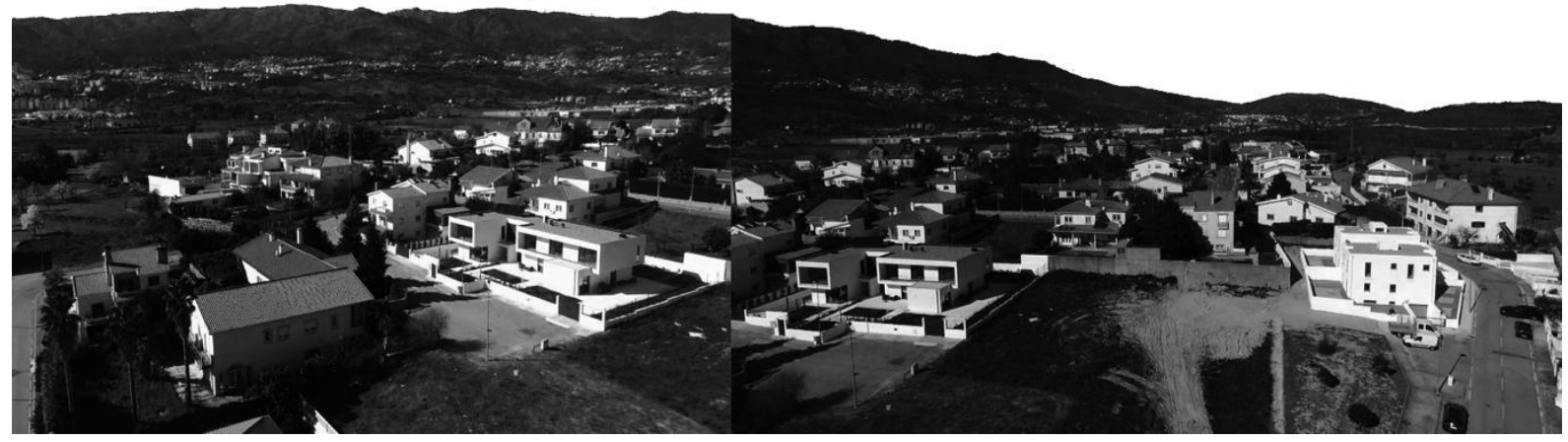

Figure 2: Case study area in Covilhã, Portugal: View of Covelo (Source: Students group - João Aparício, Maria Paula, and Sara Morais -Urban Planning Unit). 


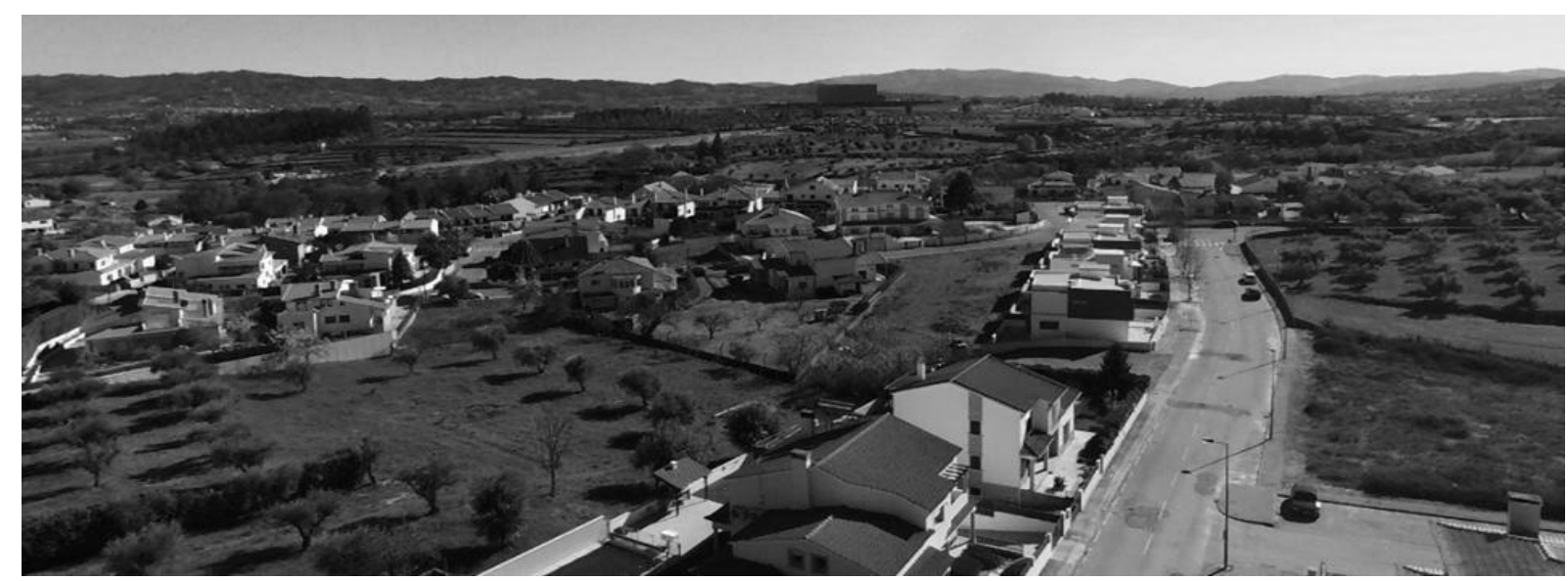

Figure 3: Case study area in Covilhã, Portugal: View of Covelo (Source: Students group - Cléa Martins, Jorge Gonzaga, Ana Oliveira -Urban Planning Unit).

The greenery is an important aspect of the city project proposals. The creation of green parks, gardens or to have trees along the streets were key aspects of the urban solutions.

The idea was to keep the ecology of the urbanization such as Niemela [2] proposes. The following urban design solution, designed by an international group comprising Portuguese and Brazilian students proposes a new green system network based on the creation of three gardens for the Covelo neighbourhood.

This green system is completed with the proposed trees along the main streets and with a high sustainability index proposed for the single house plots. Therefore, these three green spaces will be part of the public space network and will be the pivotal places for recreation activities of the inhabitants. The idea is to create a "really beautiful place, and people will slow down to be part of it" [3].

Another objective of the city project was to promote the diversity of activities, given that this neighbourhood was a typical suburbs district, focused on housing. The solutions present new plots for commercial activities and facilities (Figure 4).

The creation of public spaces such as for pedestrians and meeting areas, where people can get together for conversation and reflection was a main objective of the proposals.

For example, one of the solutions presented for Zone A, includes a central square with cafes and tea shops, as a 'pedestrian only' area, where cars are not allowed to enter (Figure 5).

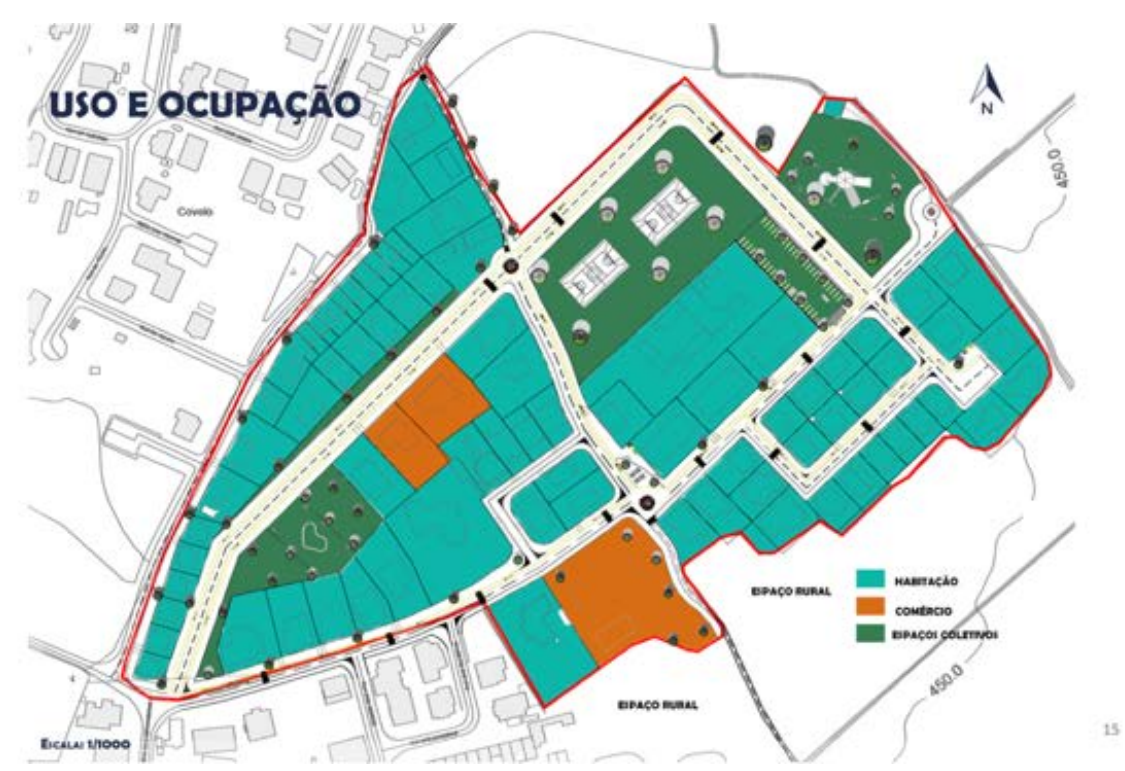

Figure 4: City Project Proposal - Zone B: Activities map (Source: International students group from Brazil and Portugal: Bruno Ferreira, João Calheiros, Marta Nunes, and Paulo Sá - Urban Planning Unit). 


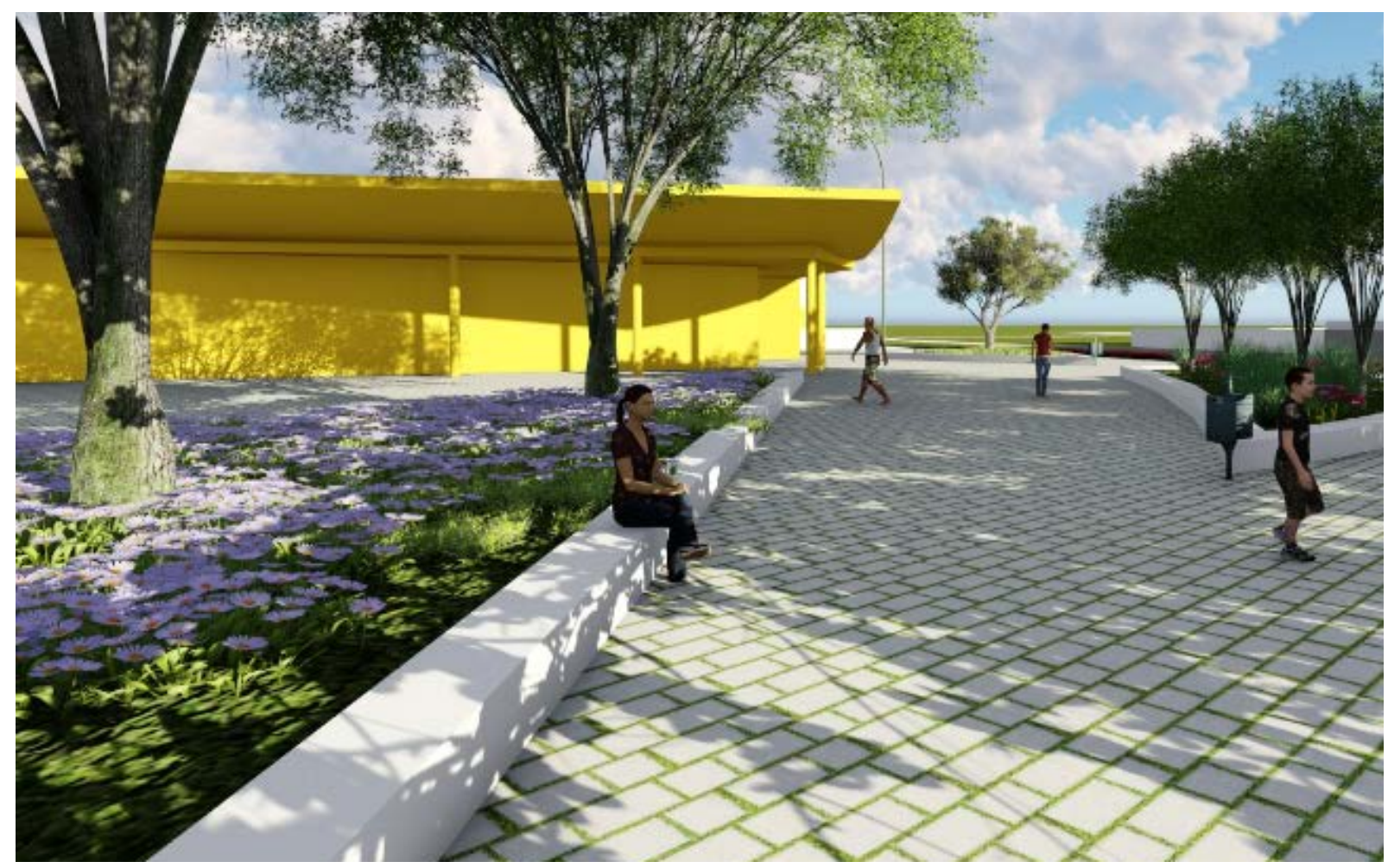

Figure 5: City Project Proposal - Zone A: 3D model of the pedestrian areas (Source: International students group from Brazil and Portugal: Daniélle Pereira, João Silva, Ricardo Sousa, and Válter Silva - Urban Planning Unit).

Given that there is no playground for kids all over this neighbourhood, the city projects for Covelo are focused on how to resolve this weakness. Therefore, there are proposals for recreational places for children.

These areas are planned to be places of attraction not only for this district inhabitants but also for families living in other parts of the city. The intention of this project is to attract new families and young couples to live in this zone, which will have plenty of public spaces for all ages including for kids (Figure 6).

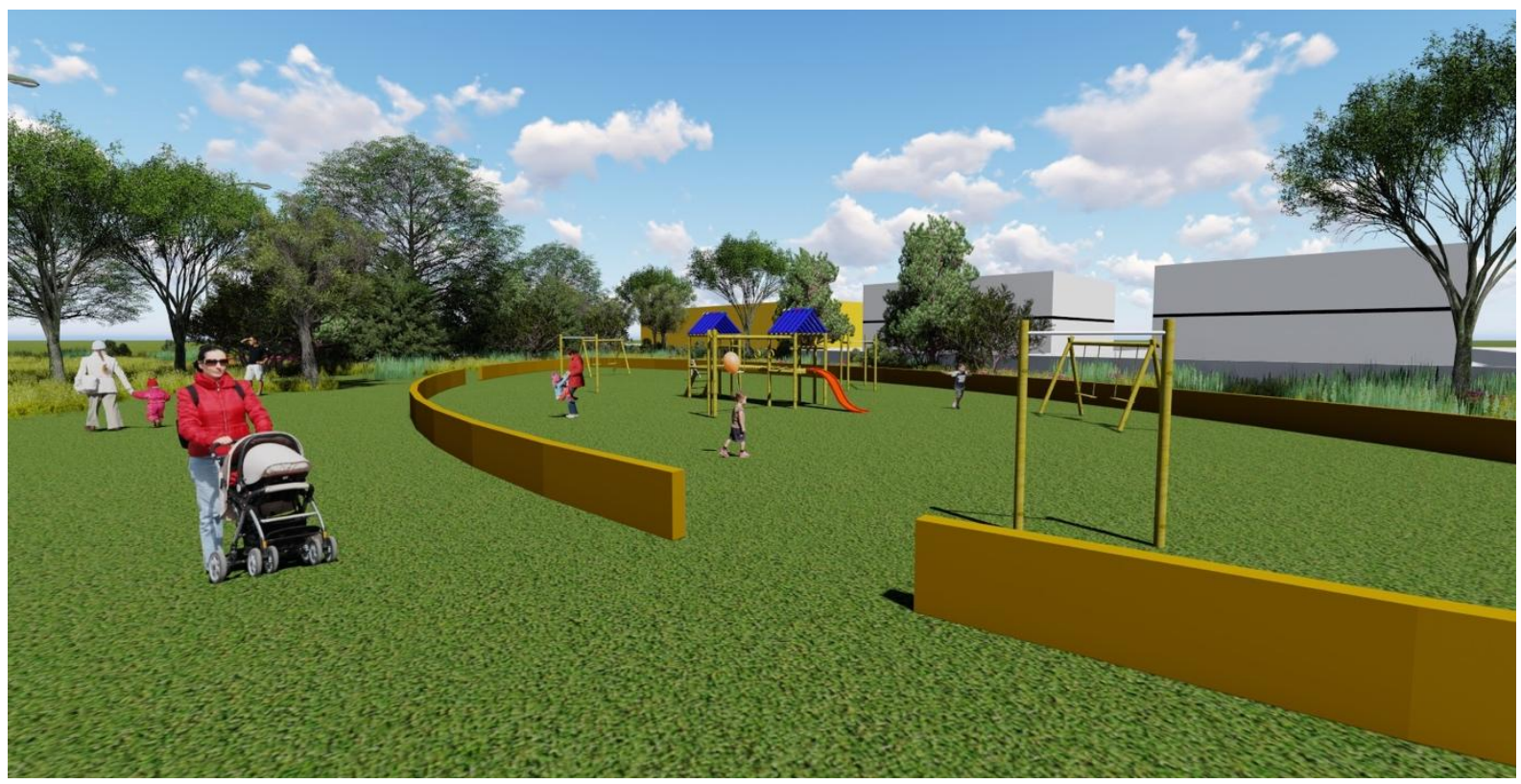

Figure 6: City Project Proposal - Zone A: 3D model of the playground area (Source: Students group Daniélle Pereira, João Silva, Ricardo Sousa, and Válter Silva - Urban Planning Unit). 
The roads network was redesigned in order to have sidewalks along to all streets. A cycling path was created in order to promote the use of the bicycle, which has the advantage of having favourable topographic conditions on the terrain. Its localization at the outskirts of Covilhã, makes Covelo one of the city's flattest districts (Figures 7 and 8).

The existing streets were redesigned with sidewalks on both sides and when possible with streets along to the car lanes. The literature confirms that among the various urban functions, mobility has a fundamental importance for the city's dynamics, as it permeates and connects the essential services to its functioning [4].

In fact, soft mobility refers to non-motorized modes of transport. It is referred as a viable alternative for reducing the problems brought about by the lack of spatial planning, especially in medium and large cities [5].

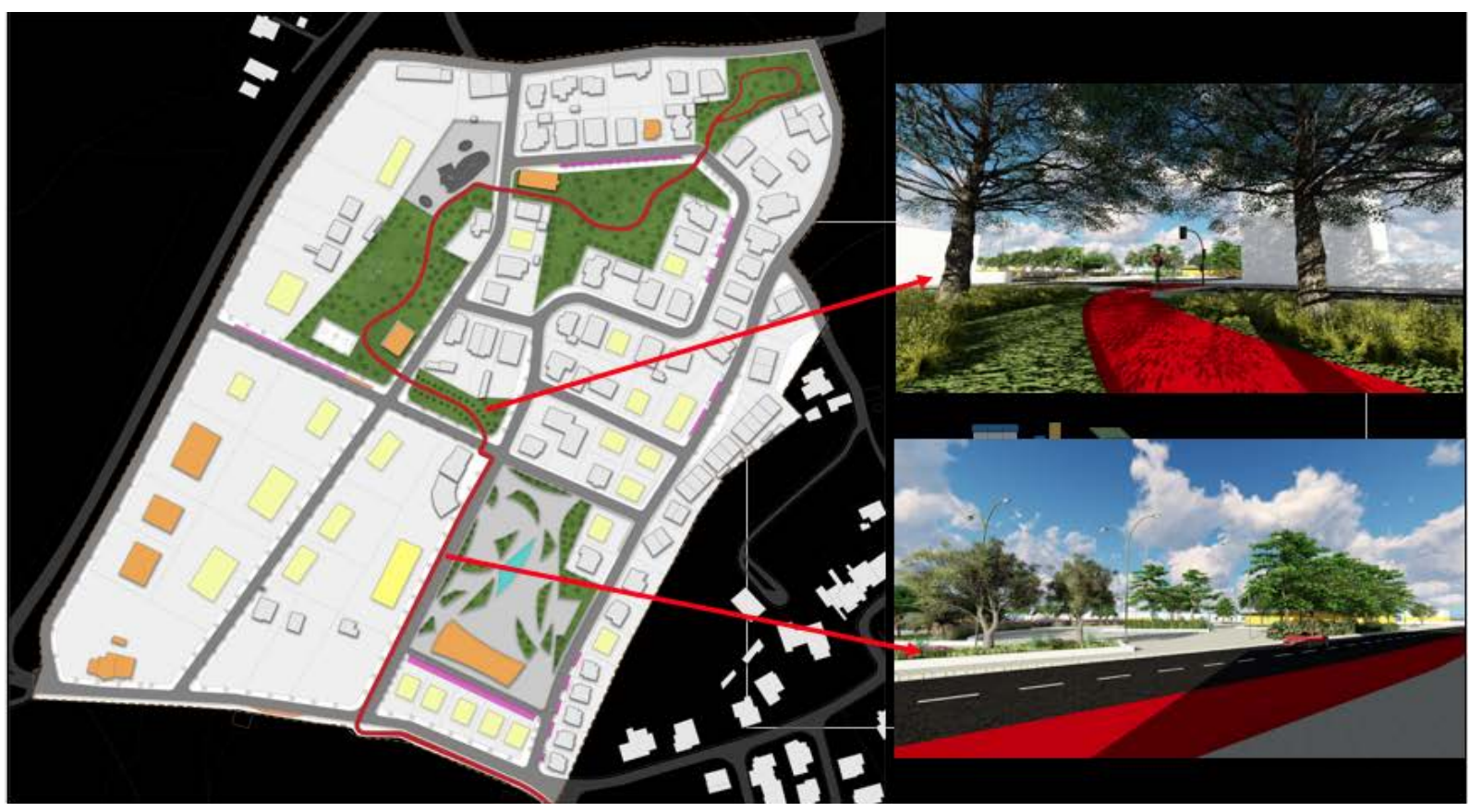

Figure 7: City Project Proposal - Zone A: 3D model of green spaces and streets (Source: Students group Daniélle Pereira, João Silva, Ricardo Sousa, and Válter Silva - Urban Planning Unit).

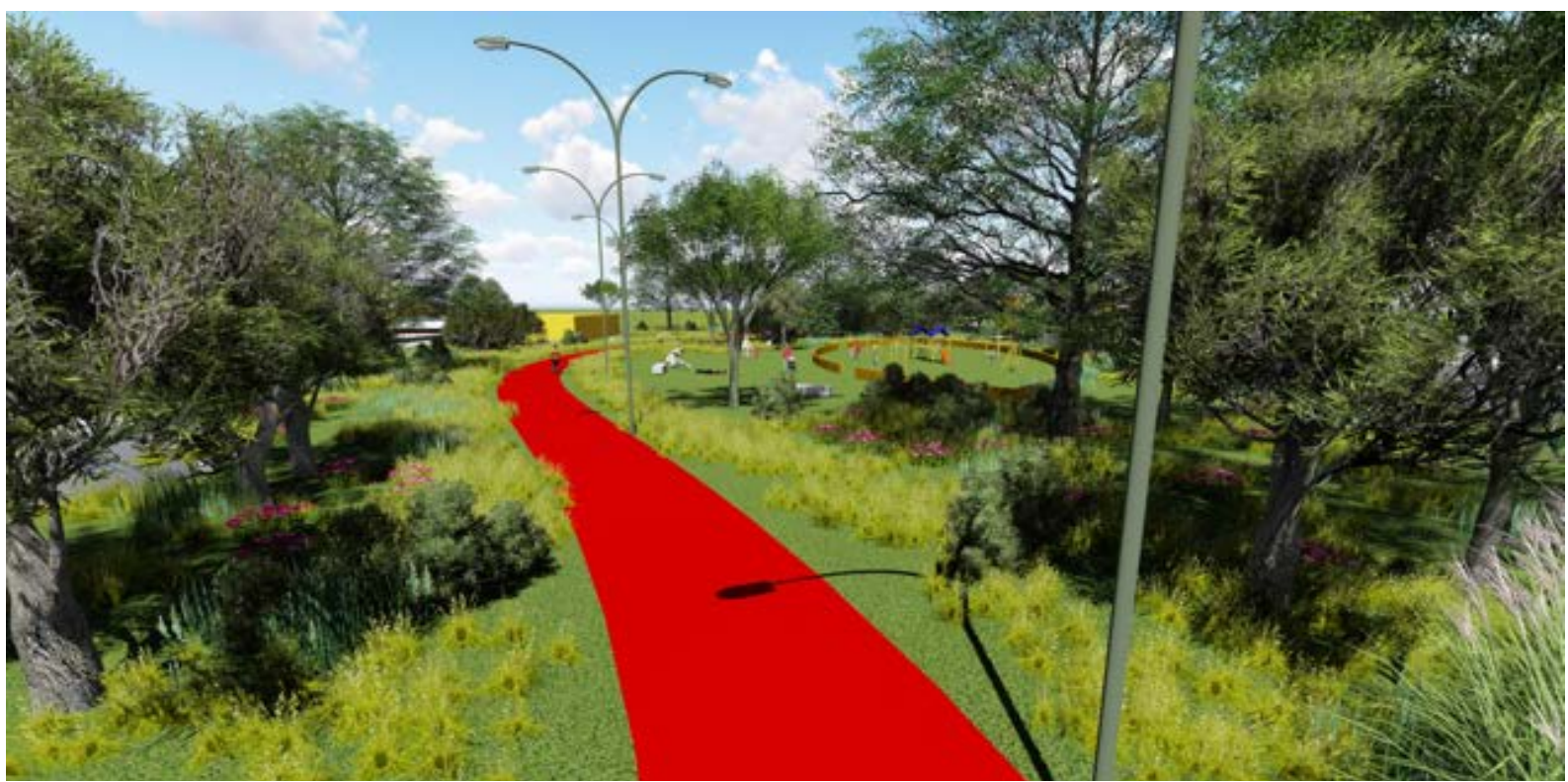

Figure 8: City Project Proposal - Zone A: 3D model of the cycling path (Source: Students group - Daniélle Pereira, João Silva, Ricardo Sousa, and Válter Silva - Urban Planning Unit). 
The promotion of "soft mobility" methods of transportation is at the top of the agenda of city regeneration, because of the advantages for urban sustainability in several terms. It is an "effective strategy to improve urban sustainability, especially in small and medium-sized cities" [6] such as Covilhã.

According to the same author, a large percentage of journeys have distances compatible with pedestrian or bicycle mobility.

In the case study area, the promotion of bicycle use aims not only to improve this soft mobility among the inhabitants on neighbourhood journeys but also as a form of mobility between Covelo and the city centre of Covilhã.

The use of bicycles has mainly been seen for recreational or sport purposes rather than has a daily mode of transport [7]. However, since 2015 that the European Union has declared cycling as an environmentally friendly way of mobility including on an urban scale [8].

\section{CONCLUSIONS}

This article has aimed to show the city projects for existing urban areas, providing several possibilities for adaptation, keeping in mind good urban design solutions.

Another conclusion regarding the presented case study area, is that the low density, detached house neighbourhoods, which have high building standards, such as the example studied of Covelo in Covilhã, always have problematic aspects which need to be resolved, improved or enhanced in urban terms.

Finally, as the previously presented examples aimed to show, the city project solutions were very keen on promoting soft mobility as an alternative.

In fact, the creation of pedestrian networks and cycling pathways was one of the most common solutions among the city project proposals, in order to encourage soft mobility.

\section{ACKNOWLEDGEMENTS}

This publication was supported by the CIAUD, the Research Centre for Architecture, Urbanism and Design, University of Lisbon, financed by FCT, the Portuguese Foundation for Science and Technology.

\section{REFERENCES}

[1] P. Allmendinger, Planning Theory, $2^{\text {nd }}$ edition, Basingstoke, Palgrave Macmillan, 2009.

[2] J. Niemela, (editor-in-chief), Urban Ecology, Patterns, Processes, and Applications, Oxford University Press, 2011.

[3] J. Green, Designed for the Future: 80 Practical Ideas for a Sustainable World, New York, Princeton Architectural Press, 2015.

[4] I. Matias, A. Virtudes, (2019a), "Bicycle Solutions in Mountain Cities: CycloCable® in Trondheim-Norway", Materials Science and Engineering, 603 (2019) 022024. DOI: 10.1088/1757-899X/603/2/022024.

[5] M. R. Silva, R. Salvalaio, J. F. G. De Brito, C. E. De Alvarez, "The bicycle as an alternative to urban mobility in medium size cities: the case study of the city of Vitória (ES), Brazil" (in Portuguese), II Encontro Nacional sobre Reabilitação Urbana e Construção Sustentável: do edifício para a Escala Urbana, Lisboa, 2017.

[6] I. Matias, A. Virtudes, (2019), "Cycling mobility in slopping cities: Trondheim and other lessons", STARTCON19 International Doctorate Students Conference + lab. Workshop in Civil Engineering, University of Beira Interior, Covilhã, 26-28 June 2019.

[7] I. Matias, B. Santos, A. Virtudes, (2019), "Making Cycling Spaces in Hilly Cities", STARTCON19 International Doctorate Students Conference + lab. Workshop in Civil Engineering, University of Beira Interior, Covilhã, 26-28 June 2019. 
[8] Presidence du Conseil de L'Union Européene - Le Gouvernement du Grand-Duché de Luxembourg - Ministère di Développement Durable et des Infrastructures, http:// www.eu2015lu.eu/en/actualites/communiques/ 2015 /10/07-info-transports-declaration-velo/07Info-Transport-Declaration-of-Luxembourg-on-Cycling-as-a-climate-friendly-Transport-Mode--2015-10-06.pdf. 